\title{
LA CODIFICACIÓN DEL DERECHO DIPLOMÁTICO: UNA PERSPECTIVA HISTÓRICA
}

\author{
The Codification of Diplomatic Lau: a historical \\ perspective
}

\author{
Blanca Sáenz de Santa María Gómez-Mampaso \\ Universidad Pontificia Comillas ICAI-ICADE \\ E-mail: bssgm@icade.comillas.edu
}

Autor

El estudio de la Diplomacia desde la historia se centra en tres focos fundamentalmente: las relaciones entre los Pueblos y las políticas que las guían, la acción de los agentes diplomáticos y los tratados entendidos como resultados de la negociación. Por ello, su análisis puede ser abordado desde múltiples perspectivas; entre ellas, el Derecho Internacional. El objetivo del presente artículo es aproximarse al proceso de codificación de la Diplomacia como rama del Derecho Internacional, desde la regulación de categorías entre los agentes diplomáticos establecida por el Congreso de Viena de 1814-1815 hasta las Convenciones de la ONU elaboradas en las décadas de 1960 y 1970.

Codificación; Derecho Internacional; Diplomacia; historia

Codification; International Law; Diplomacy; history

Key mords

The study of Diplomacy from a historic point of view is focused on three aspects mainly: the relations between Peoples and the policies that guide them, the action of diplomatic agents and treaties understood as the results of a negotiation. Therefore, we can analyze Diplomacy from multiple perspectives, including International law. The aim of this article is to approach the codification process of Diplomacy as a branch of International law from the regulation of the precedence between Diplomatic agents established by the Congress of Vienna in 1814-1815 to the United Nations Conventions developed in the 1960s and 1970s. 


\section{Concepto de Diplomacia en perspectiva histórica}

En la actualidad se emplea el término «Diplomacia» para hacer referencia a múltiples acciones que no siempre se identifican con el concepto tradicional, tales como diplomacia cultural, empresarial, no gubernamental... Sin entrar en el debate sobre lo acertado o no de su extensión a otras realidades, quisiera dejar sentado que el siguiente análisis se hace desde un enfoque que tal vez puede calificarse de excesivamente formal y academicista, puesto que parte de la premisa de que la Diplomacia es un atributo de los Estados u organizaciones políticas históricamente equivalentes, ejercido tradicionalmente por los gobiernos, y que no se puede extrapolar a otros agentes sociales. La Diplomacia, por tanto, es la disciplina que tiene por objeto el estudio de las relaciones entre los Pueblos y Estados desde la más remota Antigüedad hasta nuestros días, atendiendo para ello a la actuación de los diplomáticos en defensa de los intereses de sus respectivas organizaciones políticas a través de los tratados bilaterales o multilaterales que se firman con tal fin (Gómez Mampaso \& Sáenz de Santa María Gómez-Mampaso, 2001). Así, el estudio de la Diplomacia en perspectiva histórica se centra en tres focos fundamentalmente: las relaciones entre los Pueblos y las políticas que las guían, la acción de los agentes diplomáticos y los tratados entendidos como resultados de la negociación. En este sentido, la aproximación al fenómeno de la Diplomacia se puede realizar desde varias perspectivas; así, cuando hablamos de «Diplomacia» podemos estar refiriéndonos a las relaciones internacionales (perspectiva internacionalista) o las políticas de los Estados que las guían (perspectiva politológica), pero también puede entenderse como una rama del Derecho público del Estado conocida como Derecho externo (perspectiva iuspublicista) o, por último, como una rama del Derecho Internacional (perspectiva iusinternacionalista). Centrándome en esta última perspectiva, debemos tener en cuenta que la construcción de lo que en la actualidad conocemos como Derecho Internacional gira en torno a dos ejes: la guerra (o las maneras de evitarla) y la paz (o las formas de mantenerla), erigiéndose la Diplomacia como principal instrumento para lograr esos objetivos. Pues bien, la articulación de la Diplomacia se hace a través de lo que llamamos Derecho diplomático. Dejando a un lado las cuestiones diplomáticas que forman parte del Derecho estatal, el contenido del Derecho diplomático como rama del Derecho internacional se ha centrado históricamente en los privilegios e inmunidades de los agentes diplomáticos y en las normas relacionadas con la formación de los tratados. Ciertamente existen algunas materias cercanas, como son las relaciones consulares que suelen tratarse conjuntamente con la Diplomacia, pero que no conforman propiamente una misma institución.

A día de hoy los referentes normativos en materia diplomática son, como bien sabemos, las distintas Convenciones de las Naciones Unidas que se realizaron principalmente en las décadas de 1960 y 1970, las cuales son resultado del largo y complejo proceso que supone la codificación de una de las ramas más consensuadas dentro del Derecho internacional. Pero para poder entender el papel que desempeña la Diplomacia en el contexto internacional actual es necesario conocer cómo se han generado las reglas que la rigen, que es lo que a continuación vamos a tratar de esbozar.

\section{La teorización del derecho diplomático}

Las fuentes para la formación del Derecho Diplomático son las propias del Derecho Internacional, esto es: los Tratados, la Costumbre y los Principios generales del Derecho internacional,
En la actualidad se emplea el término "Diplomacia" para hacer referencia a múltiples acciones que no siempre se identifican con el concepto tradicional 
estando completado de forma auxiliar por la Jurisprudencia y la Doctrina. ${ }^{1}$ Ahora bien, el presupuesto de toda codificación es -o al menos debería serlo- la elaboración de una ciencia que la sustente. Para ello es necesario un proceso previo de teorización de la materia a codificar. En esta línea, la teoría de la Diplomacia no se puede concebir al margen de la teoría misma del Derecho internacional público, al ser una de sus ramas más importantes, si bien es cierto que la misma ha podido ser analizada tanto de forma adjetiva como de forma sustantiva. En cualquier caso, la teorización del Derecho internacional se remonta fundamentalmente a la Edad Moderna, si bien en aquellos tiempos la expresión que se empleaba para definir esta realidad era la de ius inter gentes.

Hasta el siglo XVI las relaciones inter gentes solo se habían abordado de forma puntual en el ámbito europeo. Así, en De civitate Dei, San Agustín (354-420) declaraba la existencia de una pluralidad de pueblos que coexisten pacíficamente sin buscar la supresión de las costumbres o leyes de cada uno de ellos, sino la consecución de un todo espiritual. Por su parte, en Etimologías v. 6, San Isidoro de Sevilla (560-636), superando la concepción del Ius Gentium romano, entendía que el Derecho de gentes era aquel practicado por todos los Pueblos, comprendiendo las normas relativas a la ocupación de lugares, la edificación, las fortificaciones las guerras, las cautividades, las servidumbres, la restitución, las alianzas de paz, las treguas, la inviolabilidad de los embajadores y la prohibición de contraer matrimonio con extranjeros. En la Baja Edad Media la ausencia de una autoridad suprema hizo que algunos destacados juristas del Ius commune comenzaran a preguntarse cómo se resolverían los conflictos entre los reinos o ciudades si no se podía acudir a una instancia superior que asegurase la resolución pacífica del mismo. En este marco surgieron el Tractatus Represaliarum y el Tractatus de insula del romanista Bartolo de Sassoferrato (1313-1357) y De bello, de represaliis et de duello del canonista Giovanni de Legnano (1320-1383). Estos textos se consideran precursores de las obras doctrinales sobre el Derecho de gentes moderno de los siglos XVI y XVII, periodo en donde realmente se hunden las raíces de la teorización del Derecho internacional.

La teoría clásica de las relaciones inter gentes la encontramos en la llamada «Escuela de Salamanca», también conocida como «Segunda Escolástica». A partir de sus teorías, el Derecho de gentes deja de entenderse como un conjunto de costumbres entre determinados pueblos para transformarse en un ordenamiento de carácter universal, es decir, aplicable a toda comunidad política, construyéndose, por tanto, sobre la base del Derecho natural aunque no por ello deja de ser también un Derecho con un contenido positivo, fruto de costumbres o pactos concretos. Los planteamientos jurídicos y teológicos del dominico Francisco de Vitoria (1483-1546) -al que se considera el fundador de esta corriente- aparecen recogidos en sus Relectiones Theologicae, un conjunto de trece lecciones o conferencias extraordinarias pronunciadas al final de varios cursos en Salamanca y que fueron publicadas póstumamente en Lyon en 1557, destacando principalmente De potestate civili, De iure belli y, sobre todo, De indis. Sus continuadores fueron numerosos, destacando especialmente Martín de Azpilicueta (1492-1586), Domingo de Soto (1494-1560), Fernando Vázquez de Menchaca (1512-1569) o Francisco Suárez (15481617). No obstante, la teoría internacional no se construyó únicamente sobre el pensamiento teológico de la Contrarreforma; dentro del ámbito protestante, Alberico Gentili (1551-1608), un civilista italiano afincado en Oxford, fue el primero en dotar de autonomía a dicha disciplina al proclamar en De iure belli (1588): «iCallad, teólogos, en lo que no es de vuestra incumben-

1 Vid. art. 38 del Estatuto del Tribunal Internacional de Justicia. 
cia!». Sin embargo, Gentili no llegó a tener la difusión que algunas décadas después tendría el holandés Hugo Grocio (1583-1645), que supo sintetizar el pensamiento de la Escuela de Salamanca, despojándola de su carácter teológico pero presentando la teoría del Derecho de gentes moderno de forma sistemática. Una de sus más importantes aportaciones fue la diferenciación entre el Derecho de gentes natural, que son los principios aplicables al Derecho de gentes y que provienen del Derecho natural, y el Derecho de gentes voluntario, que se basa en el consentimiento de los Estados. Sus dos obras más importantes son Mare liberum (1609), breve tratado sobre comercio internacional donde defiende la libertad de los mares frente al «mare clausum» propuesto por españoles y portugueses en el siglo XVI, y De iure belli ac pacis (1625), considerado como el primer tratado propiamente dicho de Derecho de gentes moderno.

Tras ellos vendrían otros autores que concretarían los principios del Derecho de gentes moderno desde planteamientos iusnaturalistas a posturas más positivistas, como Richard Zouche (1590-1661), con su Iuris et Iudicii fecialis, sive Iuris inter gentes, et quaestionum de eodem explicatio (1650); Samuel Rachel (1628-1691), con su De iure naturae et gentium (1676); Samuel Pufendorf (1632-1694), con su De iure naturae et gentium (1672); William Penn (1644-1718), con su An Essay Towards the Present and Future Peace Of Europe (1693); Gottifred Leibniz (1646-1716), con su Codex iuris Gentium Diplomaticus (1693); Charles-Irénée Castel, abate de Saint Pierre (1658-1743), con su Projet pour rendre la paix perpétuelle en Europe (1713); Christian Thomasius (1655- 1728), con su Fundamenta iuris naturae et gentium (1705); Cornelius van Bynkershoek (1673-1743), con su De Dominio Maris Dissertatio (1705) o sus Quaestionum juris publici (1737); Christian Wolff (1679-1754), con su Jus Gentium Methodo Scientifica Pertractum (1749) o sus Institutiones iuris naturae et Gentium (1750); Johann Jakob Moser (1701-1785), con su Versuch des neuesten Europäischen Völkerrechts in Friedens- und Kriegszeiten vornehmlich aus denen Staatshandlungen derer Europäischen Mächten, auch anderen Begebenheiten, so sich seit dem Tode Kayser Carls VI. im Jahr 1740 zugetragen haben (1777); Emmerich de Vattel (1714-1767), con su Le Droit des gens; ou, Principes de la loi naturelle appliqués à la conduite et aux affaires des nations et des souverains (1758); Immanuel Kant (17241804), con Zum ewigen Frieden. Ein philosophischer Entwurf (1795); y Georg Friedrich von Martens (1756-1821), con su Précis du droit des gens moderne de l'Europe, fondé sur les traités et l'usage (1789).

Todos los tratados mencionados hablan de forma tangencial de la Diplomacia, pero a lo largo de la Edad Moderna también aparecieron obras en las que se reflexionaba sobre la Diplomacia del Renacimiento y del Barroco de forma sustantiva, tales como De officio legati (1541) de Etienne Dolet; De Legationibus (1582) de Alberico Gentili; El embaxador (1620) de Juan Antonio de Vera y Zúñiga, primer conde de la Roca; el Tractatus de legato (1624) de Jean Chokier; las Advertencias para reyes, príncipes y embajadores (1643) de Cristóbal de Benavente y Benavides, primer Conde de Fontanar; L'Ambassadeur et ses Fonctions (1682) de Abraham de Wicquefort; De la manière de négocier avec les souverains (1716) de François de Callières; o De foro legatorum tam in causa civili, quam criminali liber singularis (1721) de Cornelius van Bynkershoek. En todos estos textos se reflejan las características y obligaciones del perfecto embajador moderno y constituyen útiles referentes para el conocimiento de la función diplomática, tanto desde su perspectiva iusinternacionalista como iuspublicista.

En definitiva, a lo largo de todas estas obras -y en muchas otras más- se fueron sentando las bases del Derecho de gentes, contribuyendo también a la delimitación adjetiva o sustantiva de la función diplomática como uno de sus instrumentos fundamentales. Una demostración

\section{Jeremy Bentham acuñó el término "Derecho intemacional" $y$} se le considera el primer autor que planteó la necesidad de codificarlo 
de la trascendencia de estas obras y su necesaria influencia en la construcción del Derecho internacional y su plasmación por escrito fue la iniciativa de James Brown Scott (1866-1943), fundador de la «American Society of International Law», que en 1906 propuso la formación de una colección llamada The Classics of International Law, concebida como una especie de Corpus Iuris Gentium, cuya publicación se extendería entre 1911 y 1950. Precisamente en la carta en la que presentaba su proyecto a la Institución Carnegie de Washington, expuso que lo que pretendía con la publicación de estas obras era poner a disposición de estudiantes y profesores las obras maestras del Derecho internacional, el cual no era una creación de Hugo Grocio, aunque fuera su más reconocido exponente. No pretendía con ello popularizar dicho Derecho, sino simplemente facilitar sus fuentes a la sociedad, o al menos a las personas que quisieran investigar de forma científica en los orígenes del Derecho internacional (Brown Scott, 1906).

\section{La codificación del derecho diplomático}

\subsection{Cuestiones preliminares relativas a la codificación del Derecho internacional en general}

El lector probablemente se haya sorprendido de que en la anterior relación de autores no haya sido incluido Jeremy Bentham (1748-1832), puesto que es el autor que acuñó el término «Derecho internacional». Además de por este mérito, su mención aparte se debe a que se le considera el primer autor que planteó la necesidad de codificar el Derecho internacional en sus Principles of International law, un conjunto de cuatro ensayos elaborados entre 1786 y 1789. En el primero de ellos, «Objects of International law», Bentham plantea la codificación del Derecho internacional sobre la base de dos premisas: la primera es la materia a regular, «The laws of peace would therefore be substantive laws of the international code: the laws of war would be the adjective laws of the same code», y la segunda el modo de regularla:

1. Homologation of unwritten laws which are considered as established by custom. 2 . New conventions - new international laws to be made upon all points which remain unascertained; that is to say, upon the greater number of points in which the interests of two states are capable of collision. 3. Perfecting the style of the laws of all kinds, whether internal or international. How many wars have there been, which have had for their principal, or even their only cause, no more noble origin than the negligence or inability of a lawyer or a geometrician! (Bentham, 1843, pp. 537 y ss.)

No obstante, en su Traité de Législation Civile et Pénale (1802) Bentham hacía un planteamiento totalmente distinto al hablar de un «Plan del Código Internacional», en el que lo que realmente proponía era la codificación de lo que nosotros entendemos como Derecho externo: «El código internacional es la colección de los deberes y derechos de un soberano para con los otros soberanos» (Bentham, 1839, pp. 74-75).

En cualquier caso, el punto de partida real de la codificación internacional lo encontramos en el Congreso de Viena de 1814-1815, cuyos objetivos fueron tradicionales pero sus formas absolutamente revolucionarias. Fue en Viena donde se cambiaron las reglas del juego internacional porque fue allí donde se consolidaron los tratados multilaterales propiamente dichos -un mismo documento firmado por todas las partes intervinientes- y donde podemos empezar a hablar de tratados-ley frente a tratados-contrato que habían sido característicos de la Edad Moderna. En efecto, la primera regulación multilateral de las normas de Derecho internacional público
El punto de partida real de la codificación internacional lo encontramos en el Congreso de Viena de 1814-1815, cuyos objetivos fueron tradicionales pero sus formas absolutamente revolucionarias 
aparece tímidamente en tres anexos al Acta final del Congreso de Viena de 9 de junio de 1815: la Declaración acerca de la navegación del comercio de negros (8 de febrero de 1815), los Reglamentos para la libre navegación de los ríos (arts. 108-116 del Acta Final) y el Reglamento de categorías entre los agentes diplomáticos (19 de marzo de 1815).²

A partir de ese momento se empezaron a celebrar todo tipo de congresos multilaterales que formalmente dejaban a un lado los intereses enfrentados y en los que se trataban las inquietudes comunes, primero de las grandes potencias y después de toda la humanidad. En este sentido, Carrillo Salcedo defendía que la acción colectiva de las potencias que conformaron el llamado Concierto Europeo se reflejó en tres tipos de reuniones y sus consecuentes tratados: 1) las que crearon normas al servicio de los intereses de las grandes potencias, como por ejemplo la Conferencia de Berlín, para favorecer el desarrollo del comercio y la civilización en ciertas regiones de África y asegurar a todos los pueblos la libre navegación del Congo y del Níger, firmada el 26 de febrero de $1885 ; 2$ ) las que favorecieron la cooperación institucionalizada en diversas materias, como las que crearon las comisiones fluviales (tales como la Comisión Central para la Navegación del Rin, creada 1815 por el Congreso de Viena, o la Comisión Europea del Danubio, creada en 1856 en el contexto del Congreso de París, que puso fin a la Guerra de Crimea) o las uniones administrativas (tales como la Unión Telegráfica Universal, creada por el Convenio de París de 1865 o la Unión Postal Universal, establecida por el Tratado de Berna de 1874); y 3 ) las que establecieron reglas tendentes a la protección del ser humano, cuyo máximo exponente es el llamado Derecho internacional humanitario, en el que destacan las Convenciones de Ginebra de 1865, 1906, 1929 y 1949 y las Conferencias de Paz de la Haya de 1899 y de 1907 (Carrillo Salcedo, 1991, pp. 27 y ss.).

De forma paralela, sobre todo a partir del último cuarto del siglo XIX, nos encontramos múltiples iniciativas privadas en las que se pone de manifiesto la necesidad de regulación del Derecho internacional, encontrándonos con proyectos particulares, como los Johann Kaspar Bluntschli (Das moderne Völkerrecht der civilisierten Staaten, als Rechtsbuch dargestellt, 1868), Pasquale Fiore (Il diritto internazionales codificato e la sua sanzione giuridica, 1890), Epitacio Pessoa (Projecto de codigo de direito internacional publico, 1911), Walter G. Phillimore (Phillimore's Draft submitted before the 34th Conference of the International Law Association, 1926) y Karl Strupp (Strupp's draft Code, prepared for the International Law Association, 1926), o los promovidos por diversas instituciones privadas tales como el Instituto de Derecho Internacional (1895 y 1929), la Kokusaiho Gakkwai-Asociación japonesa de Derecho Internacionla (1926), la Comisión Internacional de Jurisconsultos Americanos (1927) y la Harvard Research in International $(1932) .^{3}$

La creación de organizaciones internacionales de carácter permanente va a suponer un replanteamiento de la tarea codificadora. El Pacto de la Sociedad de Naciones, firmado en Versalles de 28 de junio de 1919, nada decía de la codificación del Derecho internacional, pero el 22 de septiembre de 1924 la quinta asamblea de la Sociedad de las Naciones resolvió crear un órgano permanente llamado Comité de expertos encargado de la codificación progresiva del Derecho internacional, compuesto por diecisiete expertos que representasen «las principales formas de civilización y los principales sistemas jurídicos del mundo» que debía preparar una

2 Vid. art. 118, apartados 15, 16 y 17 (versión consultada en Gómez Mampaso \& Sáenz de Santa María GómezMampaso, 2001, pp. 242-243).

3 Para más información consultar Naciones Unidas (1957, pp. 145-151). 
lista de temas «que hayan alcanzado un suficiente grado de madurez» susceptibles de regulación mediante un acuerdo internacional. Dichas materias serían comunicadas a todos los Estados, miembros o no de la Sociedad de Naciones, para que emitiesen sus observaciones, tras lo cual se acordaría el procedimiento a seguir y la eventual organización de conferencias para su resolución (Naciones Unidas, 2009, p. 135).

Este Comité fue constituido el 11 de diciembre de 1924. Reunidos sus miembros en Ginebra en la primavera de 1925, acordaron la conveniencia de codificar un total de once temas de Derecho internacional. A comienzos de 1926 y tras estudiar los informes preparados por un subcomité nombrado al efecto, se envió un cuestionario a los gobiernos sobre dichas materias. Finalmente en la primavera de 1927, una vez analizadas las contestaciones a dichos cuestionarios, el Comité concluyó que había cinco materias lo suficientemente evolucionadas, aunque la Asamblea decidió convocar una Conferencia en la que solo se hablaría de la codificación de tres de ellas: nacionalidad, aguas territoriales y responsabilidad de los Estados por daños causados en su territorio a la persona o los bienes de extranjeros. Dicha Conferencia se celebró en La Haya entre el 13 de marzo y el 12 de abril de 1930, pero no tuvo ningún resultado concreto. No obstante, el 25 de septiembre del año siguiente la Asamblea adoptó una resolución muy importante relacionada con el procedimiento de codificación del derecho internacional, dando varias recomendaciones que influirían notablemente en etapas posteriores (Naciones Unidas, 1957, p. 135).

Tras la Segunda Guerra Mundial, la Carta de San Francisco estableció en su art. 13, 1. que uno de los objetivos de la Asamblea General de las Naciones Unidas era el de «impulsar el desarrollo progresivo del derecho internacional y su codificación», creando mediante resolución de 11 de diciembre de 1946 la Comisión de Desarrollo Progresivo y Codificación, que al año siguiente, mediante resolución de 21 de noviembre de 1947, se transformaría en la Comisión de Derecho Internacional y que ha sido la encargada de preparar los proyectos de las convenciones para la codificación del Derecho internacional de la ONU (Naciones Unidas, 2009, pp. 5-7).

\subsection{El proceso de codificación del Derecho diplomático: de Viena 1815 a Viena 1961}

El punto de partida de la codificación del Derecho diplomático lo encontramos en el antes mencionado «Reglamento de categorías entre agentes diplomáticos» de 19 de marzo de 1815, el cual fue completado por un Protocolo del Congreso de Aquisgrán de 21 de noviembre de 1818. Ambos documentos trataban de regular sobre la base de elementos objetivos las cuestiones de precedencia entre los agentes diplomáticos que tan conflictivas habían sido durante toda la Edad Moderna (Moreno Pino, 2001, pp. 87-90).

La regulación de cuestiones diplomáticas no se va a retomar hasta principios del s. Xx. En ese momento se empieza a plantear que dentro del fenómeno diplomático la materia más fácilmente codificable es la relativa a las inmunidades y privilegios de los agentes diplomáticos. Así se pone de manifiesto en las diversas iniciativas privadas de codificación del Derecho internacional antes comentadas, pero sobre todo resulta interesante el planteamiento de la cuestión en el seno de la Sociedad de Naciones. El Comité de expertos encargado de la codificación progresiva del Derecho internacional incluyó las inmunidades y privilegios diplomáticos entre las once materias codificables, cuyo análisis por parte de un subcomité se reflejó en una interesante re-
Tras la Segunda Guerra Mundial, la Carta de San Francisco estableció que uno de los objetivos de la Asamblea General de las Maciones Unidas era el de «impulsar el desarrollo progresivo del derecho internacional y su codificación" 
solución de 8 de abril de 1925 y en la primavera de 1927 se elaboró un cuestionario relativo a la «Revisión de la clasificación de los agentes diplomáticos» para que fuera remitido a los distintos gobiernos con el objeto. No obstante, finalmente se acordó que esta materia no fuera una de las tres materias de Derecho internacional a codificar en el marco de la futura conferencia sobre codificación que se celebraría en La Haya en 1930 (Naciones Unidas, 1957, pp. 136-137).

El primer resultado concreto en esta materia a nivel internacional lo encontramos en un ámbito multilateral y regional: la VI Conferencia Internacional Americana, celebrada en La Habana en 1928. Una de las varias convenciones que se acordaron bajo el amparo de la Unión Panamericana era la relativa a los funcionarios diplomáticos, firmada el 20 de febrero de ese año, siendo aplicable tanto a misiones ordinarias como extraordinarias. ${ }^{4}$

Para un intento de regulación internacional multilateral a nivel universal habría que esperar a los trabajos de la Comisión de Derecho Internacional de la ONU. En 1949 se formó un memorándum titulado «Examen del Derecho Internacional en relación con los trabajos de codificación de la Comisión de Derecho Internacional», donde se proponían catorce temas susceptibles de ser codificados estando el derecho de los tratados en el puesto núm. 10 y las relaciones e inmunidades diplomáticas en el puesto núm. 11. En este sentido, se tenía muy claro que «la tarea confiada a la Comisión de Derecho Internacional en esta materia no concierne solamente a las inmunidades y privilegios diplomáticos, sino a los diversos aspectos de las relaciones diplomáticas en general». Así, en años posteriores, sobre todo en las décadas de 1960 y 1970, fueron formándose los distintos textos que conforman la base legal internacional de la Diplomacia -y materias vinculadas- y que son:

1. Convención de Viena sobre Relaciones Diplomáticas, 18 de abril de 1961.5

1.1. Protocolo adicional a la Convención de Viena sobre Relaciones Diplomáticas sobre adquisición de la nacionalidad, 18 de abril de $1961 .^{6}$

1.2. Protocolo adicional a la Convención de Viena sobre Relaciones Diplomáticas sobre sobre la Jurisdicción Obligatoria para la Solución de Controversias, 18 de abril de 1961 . $^{7}$

2. Convención de Viena sobre Relaciones Consulares, 24 de abril de $1963 .{ }^{8}$

2.1. Protocolo adicional a la Convención de Viena sobre Relaciones Diplomáticas sobre adquisición de la nacionalidad, 24 de abril de 1963.9

2.2. Protocolo adicional a la Convención de Viena sobre Relaciones Diplomáticas sobre sobre la Jurisdicción Obligatoria para la Solución de Controversias, 24 de abril de $1963 .{ }^{10}$

3. Convención de Viena sobre el Derecho de los Tratados, 23 de mayo de 1969. ${ }^{11}$

Según consta en la United Nations Treaty Collection se han adherido un total de 190 Estados de los 193 que componen en la actualidad la ONU.

6 Un total de 51 de los 193 Estados miembros de la ONU se han adherido a este tratado (Ibid. cit.).

7 Un total de 70 de los 193 Estados miembros de la ONU se han adherido a este tratado (Ibid. cit.).

8 Un total de 177 de los 193 Estados miembros de la ONU se han adherido a este tratado (Ibid. cit.).

9 Un total de 40 de los 193 Estados miembros de la ONU se han adherido a este tratado (Ibid. cit.).

10 Un total de 51 de los 193 Estados miembros de la ONU se han adherido a este tratado (Ibid. cit.).

11 Un total de 114 de los 193 Estados miembros de la ONU se han adherido a este tratado (Ibid. cit.).

\section{La Diplomacia} tradicional y legal no puede dar la espalda a la realidad social y a los nuevos espacios de relación intemacional con nuevos actores que hacen necesario redimensionar el fenómeno diplomático 
4. Convención de Nueva York sobre Misiones Especiales, 8 de diciembre de 1969. ${ }^{12}$

4.1. Protocolo adicional a la Convención de Viena sobre Relaciones Diplomáticas sobre sobre la Jurisdicción Obligatoria para la Solución de Controversias, 8 de diciembre de $1969 .{ }^{13}$

5. Convención de Viena sobre Representación de los Estados en sus relaciones con las Organizaciones Internacionales de carácter universal, 14 de marzo de $1975 .{ }^{14}$

\section{A modo de conclusión: ¿un nuevo Derecho Diplomático para una nueva Diplomacia?}

Desde el Derecho internacional actual la Diplomacia se concibe como un instrumento propio de los Estados nacionales de corte occidental cuyos actores fundamentales son los agentes diplomáticos y está orientada a la conclusión de tratados. Por otra parte, existen realidades cercanas, como son las relaciones consulares, que históricamente no han sido analizadas de forma independiente y que en la actualidad tampoco se pueden separar.

No obstante, esta Diplomacia tradicional y legal no puede dar la espalda a la realidad social y a los nuevos espacios de relación internacional con nuevos actores que hacen necesario redimensionar el fenómeno diplomático. En las líneas anteriores se ha tratado de hacer un breve esbozo de los fundamentos doctrinales y legales de la Diplomacia tradicional. Cualquier aproximación o reformulación que se desee hacer en este sentido tiene que pasar necesariamente por una reflexión sobre estos presupuestos.

\section{Bibliografía}

Bentham, J. (1839). Compendio de los Tratados de legislación civil y penal, de Jeremías Bentham con notas, por D. Joaquín ESCRICHE, Abogado de los tribunales del reino (2a ed.). Madrid: Librería de la Viuda de Calleja e Hijos.

Bentham, J. (1843). The Works of Jeremy Bentham, published under the superintendence of his executor John Bowring. Londres y Edimburgo: Simpkin, Marshall \& Co.

Brown Scott, J. (1906, 02 de noviembre). Letter from James Brown Scott, Solicitor of the Department of State, to R.S. Woodward, President of the Carnegie Institution of Washington, relative to a project for the Republication of the Classics of International Law. En J. Brown Scott (Ed.), (1911), The Classics of International Law. Washington, D. C.: Carnegie Institution.

Carrillo Salcedo, J. A. (1991). El Derecho internacional en perspectiva histórica. Madrid: Tecnos.

Eyffinger, A. (2012). Diplomacy. En B. Fassbender \& A. Peters (Eds.), The Oxford Handbook of the History of International Law. Oxford: Oxford University Press.

12 Un total de 38 de los 193 Estados miembros de la ONU se han adherido a este tratado (Ibid. cit.).

13 Un total de 17 de los 193 Estados miembros de la ONU se han adherido a este tratado (Ibid. cit.).

14 Un total de 34 de los 193 Estados miembros de la ONU se han adherido a este tratado (Ibid. cit.). 
Gómez Mampaso, M. V. \& Sáenz de Santa María Gómez-Mampaso, B. (2001). Una aproximación a la Historia de las Relaciones Diplomáticas (Texto y Documentos). Madrid: Publicaciones de la Universidad Pontificia Comillas.

Moreno Pino, I. (2001). La Diplomacia. Aspectos teóricos y prácticos de su ejercicio profesional. México, D. F.: Secretaría de Relaciones Exteriores-Fondo de Cultura Económica.

Naciones Unidas (1957). Relaciones e inmunidades diplomáticas. Documento A/CN.4/98: Memoria presentada por la Secretaría. En Naciones Unidas, Anuario de la Comisión de Derecho Internacional, 1956. Vol. II. Nueva York: Naciones Unidas. Recuperado de http://legal.un.org/ilc/publications/yearbooks/spanish/ilc_1956_v2.pdf

Naciones Unidas (2009). La Comisión de Derecho Internacional y su Obra. 7. ${ }^{a}$ Ed., Vol. I. Nueva York: Naciones Unidas. Recuperado de http://conf.unog.ch/esportal/sites/default/files/ Work-ILC-7th\%20Ed-07-Vol\%20I-S.pdf

Naciones Unidas. (s. f.). United Nations Treaty Collection. Recuperado de https://treaties. un.org/

Nicholson, H. (1948). La Diplomacia. México, D. F.: Fondo de Cultura Económica. 